\title{
CONCEITO DE DESAGREGAÇÃO EM PSIQUIATRIA
}

\author{
Maurício Levy Junior *
}

Desagregação, desagregado, são palavras de uso corrente em psiquiatria. Fala-se de desagregação verbal, ideativa, do pensamento, intelectual, mental ou psíquica, da personalidade (significados de extensão crescente). Simplificando, vamos abordar: a) a desagregação do pensamento; b) a desagregação mental ou psíquica.

"Por desagregação", diz Schneider ", "entende-se o fato de que as conexões de um pensamento não podem ser seguidas pelas demais pessoas $\cdot$, para o observador, um pensamento carece de relação com aquilo que o precede. E' indubitável que, em certas ocasióes, os esquizof rênicos falam e pensam dêste modo; porém é indiscutivel, também, que graus ligeiros de desagregação podem observar-se em tôda a parte. Desagregadas, neste sentido, o são muitas pessoas, por natureza, e outras, em parte, em situações excitantes como, por exemplo, na embriaguez ou sob a ação da febre. 0 pensamento confuso pode ser qualificado, também, de "desagregado". Em sentido lato, portanto, os têrmos "desagregação" e "desagregado" podem ser utilizados para qualificar o pensamento em diversos estados, fisiológicos e patológicos: 1) na sonolência e na fadiga; 2) nos estados confusionais (psicoses sintomáticas, epilepsia, estados crepusculares psicogenéticos); 3) nas síndromes esquizof rênicas; 4) em estados demenciais (psicoses orgânicas).

Preferimos, entretanto, empregar terminologia mais precisa, fazendo distinção entre pensamento desagregado, pensamento incoerente e pensamento demencial. 0 primeiro seria peculiar às síndromes esquizofrênicas (esquizofrenias ou patoplastias esquizofrênicas); o segundo caracterizaria os estados confusionais; o terceiro refere-se aos estados demenciais.

Lange $^{2}$ assim descreve o pensamento desagregado: "Lucidez de consciência com conceitos que se desintegram, junto a outros que se conservam intactos; claudicação geral da atitude intencional necessária para o pensamento ordenado; mudança brusca do objetivo do pensamento com falha das tendências determinantes. A mistura variada e a mudança rápida dêstes traços dão ao pensamento esquizofrênico seu caráter extravagante, saltuário, ilógico, caótico. As manifestações intelectuais do esquizof rênico resultam, em certas ocasióes, mais estranhas porque a linguagem pode desviar-se por sua conta, empregando-se palavras falsas para conceitos normais ou bem, utilizando-se, para conceitos esquizof rênicos, palavras que habitualmente possuem outro significado". E, em outro lugar, apesar de tudo, a forma exterior do discurso pode resultar completamente ordenada nos es-

\footnotetext{
* Psiquiatra do Hospital de Juqueri.
} 
quizof rênicos. Como diz Bumke, "muitas manifestações esquizofrênicas podem caracterizar-se pelo fato de que os maiores absurdos são apresentados sob a forma de um discurso cheio de sentido".

Atribuindo a desagregação do pensamento às síndromes esquizof rênicas, devemos, para melhor compreendê-la, abordar, ràpidamente, a psicopatologia do pensamento esquizof rênico, aliás, ainda bastante discutida.

Para Bleuler, o distúrbio central seria a diminuição ou abolíção da tensão associativa (Störung der Assoziationsspannung); Bleuler fala de um distúrbio oniróide da associação (traumhafte Assoziationsstörung). Segundo Bumke, "a essência do pensamento esquizof rênico consiste em que a unidade do pensamento se rompe, separando o conexo e unindo o desconexo e heterogêneo em uma só vivência". Grühle, ao estudar a psicopatologia dos esquizof rênicos, admite, como transtôrno essencial do pensamento, o da iniciativa (Initiativstörung). Beringer acentua a falta de ordenação hierárquica das idéias. Para Kleist, é fundamental a orientação paralógica do pensamento (paralogische Aktivierungsstörung).

Quer-nos parecer que o pensamento desagrcgado do esquizof rênico apresenta dois distúrbios fundamentais, em geral tanto maiz acentuados quanto mais grave a desagregação: 1) Afrouxumento da capacidade de direção do pensamento, da intencionalidade, da iniciativa do pensar (Grïhle). E' o enfraquecimento ou rotura do "arco intencional" (Beringer), rotura essa que facilitaria o aparecimento de outros distúrbios, inclusive uma franca desagregação. 2) Mecanismo associativo fazendo-se de maneira inconipreensível para o indivíduo normal. O pensamento toma uma orientação paralógica (Kleist); as associações afastam-se das possibilidades reais e lógicas (pensamento autístico), perdendo "as características adquiridas pela experiência", ao contrário do que acontece na fuga de idéias e nos distúrbios associativos doss orgânicos ${ }^{3}$.

Empregando terminologia freudiana, podemos dizer que, então, o processo psíquico secundário (do pensamento lógico, consciente, realista) é parcialmente substituído pelo processo primário (do inconsciente) ${ }^{4}$, com suas condensações e deslocamentos, conforme veremos.

Finalmente, outras manifestações esquizof rènicas podem contribuir para acentuar a desagregação (interceptações, erupção ou impasição de pensamentos, estereotipias, verbigerações, neologismos, maneirismos, perseveração).

A desagregação torna-se, às vêzes, tão acentuada que nada do que o doente exprime é compreendido. E' a chamada salad:l verbal ou esquizofasia. Nestes casos, os distúrbios do pensamento são acrescidos por distúr. bios concomitantes da linguagem. Kleist e seus discípulos separam, da esquizof renia vera ou embotamento incoerente (inkohärentes Verblödung) esquizofrenia sensu striclo - a forma denominada esquizofasia. Naquela, o distúrbio é pré-verbal; nesta, processa-se na etapa verbal. Naquela, as alterações localizatórias seriam fronto-occipitais; nesta, fronto-temporais.

A comparação com os fenômenos oníricos ajuda-nos a compreender melhor diversos distúrbios esquizof rênicos, entre êles a desagregação. Já Freud havia afirmado que "o estudo do sonho deve ser considerado como o cami- 
nho mais seguro para a investigação dos mais profundos processos animi$\cos ^{\prime \prime}$.

Para a elaboração onírica, nosso psiquismo inconsciente utiliza-se de uma série de mecanismos - condensações, deslocamentos, simbolizações -.que permitem a exteriorização das idéias latentes sob a forma do chamado conteúdo manifesto do sonho.

$\mathrm{Na}$ esquizofrenia, podemos dizer que as fôrças inconscientes invadem patològicamente, em grau variável, o psiquismo desperto e adaptado à realidade, do doente. $O$ que, durante o sono se realiza no sonho, verifica-se. parcialmente, muiatis mutandis, no viver esquizofrênico. No sonho, o inconsciente se manifesta pelas imagens oníricas; na vida desperta do esquizofrênico, dispõe, o inconsciente, de maiores meios de expressão, utilizando-se tanto das representações e das palavras, como das ações. Muitas ma. nifestações mórbidas, tidas por absurdas e incompreensiveis, deixam de o ser desde que - à luz do que afirmamos - se interpretem, conveniente. mente, os mecanismos subjacentes de condensação, deslocarnento e simbolização. Como exemplos, podemos citar: a) Uma mulher ${ }^{6}$, aborrecida por abandonar sua situação de "apôio", como dama de companhia de dona de casa, experimenta, agora, uma aversão irresistível por tudo que se assemelhe a um apôio, a um bastáo; b) Ùma paciente, Maria L.', se arremessa contra as enfermeiras, para arrebatar-lhes as chaves; precipita-se, furiosa, sôbre uma mesa na qual vê um bule de café e quer derrubá-lo. Explicação: ela se vê numa luta entre o céu e o inferno, entre o bem e o mal; sua mis. são é defender o céu. A côr prêta (do café) é a côr do diabo; as chaves, eram as chaves do céu. A doente aceita os símbolos pela realidade ou. inversamente, as coisas reais por símbolos *.

* A comparação com o sonho - vímo-lo -.. é lícita e esclarecedora. Tal não parece ser o caso quando a analogia se faz com o pensamento primitivo. O pensamento normal é realista, adaptado à realidade. Por sua capacidade de pensar, o homem chega ao conhecimento do real. No sonho, ao contrário - e, também, em parte, na esquizof renia - o pensamento não é um conhecimento, um voltar-se para o mundo, objetivo ou subjetivo, mas apenas um modo de expressão (Dalbiez). No dizer de Bleuler, trata-se de um pensamento derreista ou autista (dereistiches Denken), sem alcance pragmático. Ora, no selvagem, o pensamento, se bem que primitivo, mais próximo a elementos intuitivos ou sensíveis, mais dependente de fatôres catatínicos e com tendências mágicas - não é, entretanto, apenas expressivo (como no caso do pensamento derreista), porém principalmente cognitivo e realista. Parece-nos, pois, imprópria, a equiparação feita por alguns autores entre o psiquismo primitivo e o esquizof rênico.

$O$ pensamento esquizof rènico, entretanto, se aproxima - como, aliás, o do sonho - do primitivo por um característico importante: a regressão (tópica, cronológica e formal). Aproxima-se, sem, porém, se assemelhar demasiado. Poderíamos, para esclarecimento, fazer uma comparação com a biologia. Segundo a lei biogenética fundamental (Haeckel), “a ontogênese é uma repetição abreviada e modificada da filogênese". $O$ embrião humano, por exemplo, passaria por uma etapa branquial, lembrando os peixes e os girinos. Entretanto, se, por um processo qualquer, um feto pudesse regredir a essa etapa branquial, jamais poderiamos equipará-lo aos peixes e girinos. Estes são adaptados à realidade, são capazes de ajeitar-se ao meio ambiente, ao passo que o embrião, em sua etapa branquial, apenas poderia exprinir uma fase evolutiva, imprópria para viver na realidade. 
Visto, assim, em linhas gerais, o que entendemos por desagregação do pensamento, passemos, agora, a um exemplo. Antes, porém, convém acentuar que, no pensamento desagregado, apesar da ausência de uma clara representação teleológica, freqüentemente se entrevê a influência de uma idéia diretriz: após uma série de saltos entre frases ou fragmentos de frases, o pensamento pode voltar ao "tema" fundamental. De qualquer modo, porém, há um afrouxamento da capacidade de direção do pensamento e a incapacidade para a resolução de novos problemas. Faltam, ao esquizof rênico, as relações do todo com a parte, e a hierarquização das associações.

Pedimos a uma paciente esquizof rênica (M. A. G., 43 anos, branca, brasileira, casada, internada no Hospital Central do Juqueri - R. G., 24.186), com nítida desagregação ideativa, que nos explicasse determinados provérbios, quer escrevendo uma pequena história, quer por outro meio qualquer. Eis dois dos resultados obti$\operatorname{dos}^{*}$ :

1 - "Falar é prata, calar é ouro" - Resposta: "Curiosidade inaudita!... E o cherife mostrando a sala de armas ao rapaz disse: agora você me explica porque é que tôdas pessóas que eu conheço todo instante à dizer "Falar é prata, calar é ouro". $O$ coitadinho então ficou ruborizado pegou um punhal reluzente cravou no peito dizendo: "De uma facada eu morro!!!"

2 - "A preguiça é a mãe de todos os vícios" - Resposta: "História em Chiméra !.. Havia um Rey muito poderoso. Um dia apareceu um chamado telegráphico em cima da escrivaninha vindo do Estados-Unidos que dizia - Venha Rey Brasil! sem Rainha. Norte-America. Quando foi na hora do trabalho o Rey ficou surprehendido mas bastante alegrc. Leu umas dez vezes o telegrama depois pêgou o phone e comunicou à Raynha fazendo nesse momento as despedidas! d'ahi a meia hora um navio do Corpo-Escola partia levando o Rey e uma grande comitiva. A Raynha chorava! mas chorava tanto!? que até quasi os mosquitos perderam as azas de tanta aflição que aquele chôro espalhava!!!! Quando foi daqui a pouco?! deu um estrálo!? a parêde se abriu e apareceu S." Ex." o isterismo: um rapaz mais lindo deste mundo dizendo n'uma gargalhada... unica A preguiça é a mãe de todos os vicios!!! - e acabou-se a historia."

Outro exemplo, ocorrido conı W. S., 16 anos, branca, brasileira, solteira, R. G. 36.24.8.

"Falar é prata, calar é ouro" - Resposta: "Falar é a explicação, são os panoramas das carnes, couros dos crocodilos que serve para fazer sapatos que tantos as moças e senhoras distintas usam; calar do tezouro que são as semelhanças do coração, os filhos, as crianças inocentes."

Finalmente, vejamos as principais diferenças que, com o pensamento desagregado, apresentam: a) o pensamento incoerente; b) o encontrado nos estados de demênci: orgânica; c) a fuga de idéias.

a) Aplica-se o têrmo "incoerente" quando, às conexóes ideativas incompreensíveis - também existentes na desagregação esquizof rênica - adicio. nam-se distúrbios da consciência (obnubilação, estados crepusculares). 0 pensamento incoerente distingue-se, pois, fàcilmente, do pensamento desa-

* Respeitadas a ortografia c a pontuação da paciente. 
gregado porque èste é acompanhado de lucidez, enquanto que naquele há transtornos da consciência (Lange, Bumke, Stransky, Mayer-Gross, Jahrreiss). Dois são os principais casos em que encontramos a incoerência do pensamento: 1) confusão mental das psicoses sintomáticas; 2) estados crepusculares epilépticos (nestes, há maior lentidão, perseveração e viscosidade).

b) Quanto-ao pensamento, muitas vêzes saltuário e alógico, dos estados demenciais, relativamente fácil é diferençá-lo da desagregação esquizofrênica. Na desagregação, predomina o distúrbio qualitativo; a demência é uma alteração quantitativa. Aquela é mais um desvio (paralógico) ; esta, um déficit. Na desagregação (Zerfahrenheit, de Kraepelin) encontramos os fenômenos particulares de interceptação, escapamento, erupção ou imposição de pensamentos, aos quais se junta ou serve de base a orientação paralógica da inteligência (condensações, simbolizações, deslocamentos). As faculdades intelectuais se desviam, perdem certas capacidades de açâo, mas não se desmoronam. Há lucidez da consciência. A memória, a atenção, a compreensão podem estar perfeitamente conservadas. Na demência, há empobrecimento intelectual permanente. Ressaltam, no pensamento, a pobreza dos conceitos e os déficits alógicos, fàcilmente compreensíveis à luz dos distúrbios concomitantes, a saber: alteraçōes das funções mnésticas (memória pròpriamente dita, fixação e reprodução), com diminuição do número dos conceitos disponiveis; dificuldade da apercepção; falta de agilidade e lentificação dos processos mentais; redução do horizonte psíquico. $\mathrm{Na}$ demência, podemos dizer que há verdadeiro desmoronamento da inteligência (Zerfall).

c) Na fuga de idéias o pensamento perde, completamente, o "fio condutor", com mudança contínua da representação final. Mas o que caracteriza o distúrbio é a maneira compreensível por que se efetuam as associações das idéias, "com supremacia das associações exteriores e das palavras (assonância) sôbre os interiores" (Bleuler). Na desagregação, as conexões são incompreensíveis; pelo contrário, na fuga de idéias, "elas são normais entre membro e membro e, em certas ocasiões, até se tornam mais visíveis que no pensamento normal, devido, precisamente, à falta de representação superior" 8 .

\section{DESAGREGAÇAO MENTAL OU PSIQUICA}

No indivíduo normal, as diferentes funções dos três setores da personalidade - cognitivo, afetivo e conativo - trabalham harmônicamente, permitindo-lhe estabelecer contacto adequado com a realidade, compreendê-la $\mathrm{e}$ atuar sôbre ela, pragmàticamente. Esta unidade funcional da mente pode estar mais ou menos comprometida. Tal transtôrno - ausência de coesão e de harmonia das diferentes funções psíquicas entre si e com o ambiente constitui a desagregação mental.

A desagregação mental pode ser entendida em dois sentidos: 1) Num sentido lato, é desagregação mental tôda perda das conexões normais de determinada função psíquica. Por exemplo, todo $n$ doente que apresente fe- 
nômenos de automatismo mental, seria um desagregado. Genil Perrin ${ }^{3}$ apõe o rótulo "desagregação da personalidade" aos casos de automatismo mental. 2) Num sentido mais restrito, desagregação mental significa esquizof renia ou esquizomorfia.

Bleuler, estudando a demêhcia precoce, de Kraepelin, preferiu denominá-la - visto nem sempre ser precoce, nem demência pròpriamente dita de esquizofrenia, porque "seu característico mais importante é a cisão das diversas funções psíquicas" ${ }^{10}$. Por essa mesma razão, àlguns autores, referindo-se à esquizofrenia ou demência precoce, falam de "desagregação da individualidade" (Wernicke), "ataxia intrapsíquica" (Stransky), "discordância" (Chaslin), "perda de unidade interior" (Kraepelin), "doentes dissaciados" (Anglade).

A desagregação manifesta-se, tanto pela incoordenação das diversas funções psíquicas entre si - o que fêz Minkowski dizer, liguradamente, que o atingido é o "espaço intersticial" 11 - como pela falta de adaptação de cada função ao real [perda do contacto vital com a realidade (Minkowski ${ }^{12}$ )] "Os conteúdos do pensamento nem resultam adequados entre si, nem conduzem a uma ressonância emotiva compreensível, nem tampouco às ações correspondentes" (Lange ${ }^{13}$ ). Esta dissociação ou desagregação da vida psíquica do doente é o verdadeiramente "esquizof rênico".

Entretanto - quer-nos parecer - como acentua Burnke, o fenômeno psíquico, ainda que mórbido, constitui uma unidade. E, se para o indivíduo normal uma reação afetiva ou uma ação motora de um esquizof rênico podem parecer discordantes, consideradas do ponto de vista do doente, das modificações globais sofridas por seu psiquismo, talvez sejam perfeitamente consonantes.

"Recordemos também aqui, diz Bumke ${ }^{14}$,"as relações com respeito a nossos sonhos. $O$ individuo são pode experimentar, em sonhos, as mais terríveis coisas sem o correspondente eco emocional e nêle esta contradição resulta, seguramente, de comparar, num juízo a posteriori, o pensar onírico com o pensar da vigília. Mas é preciso ver que, para êle, as coisas tiveram, em sonho, outro significado".

\section{BIBLIOCRAFIA}

1. Schneider, Kurt - Problemus de Patopsicologia y de Psiquiatria Clínica. Trad. espanhola, Ed. Xavier Morata, Madrid, 1947, pág. 56.

2. Lange, J. e Bostroem, A. - Psiquiatria. Trad. Espanhola, Ed. Miguel Servet, Madrid, 1942, pág. 50.

3. Bleuler, E. - Lehrbuch der Psychiatrie. Ed. Julius Springer, 3.* edição, Berlin, 1920, pág. 57.

4. Freud, S. - Obras completas. Vol. 9, Metapsicologia. Trad. Espanhola de Ballesteros y de Torres. Ed. Americana, Buenos Aires, pág. 176.

5. Freud, S. - Loc cit.4, vol. 3, pág. 284.

6. Bleuler, E. - Loc. cit.3, pág. 280. Idem em Kretschmer, "Medicina Psicológica". 
7. Minkowski, cit. por Dalbiez, R. - $\mathrm{O}$ método psicanalítico e a doutrina de Freud. Tradução brasileira de J. Leme Lopes, Ed. Agir, Rio de Janeiro, 1947, tomo I, pág. 24.9.

8. Bumke, O. - Nuevo Tratado de Enfermedades Mentales. Tradução espanhola da 5.* edição alemã, Ed. F. Seix, 1946, pág. 86.

9. Genil Perrin - Les Paranoïaques. Ed. Maloine, Paris, 1926, págs. 44 e 99.

10. Bleuler, E. - Dementia praecox oder Gruppe der Schizophrenien. In Manual de Psiquiatria de Aschaffenburg, 4.* parte, Vol. 1.

11. Minkowski, E. - La Schizophrénie. Ed. Payot, Paris, 1927, pág. 80.

12. Minkowski - Loc. cit.11, pág. 77-87.

13. Lange, J. - Loc. cit.2, pág. 268.

14. Bumke, O. - Loc. cit.8, pág. 716.

R. Barão de Itapetininga $273,60^{\circ}$ andar - São Paulo. 